Psychology of Language and Communication 2013, Vol. 17, No. 3

VERSITAOPEN

DOI: $10.2478 /$ plc-2013-0016

\author{
MITCHELL RABINOWITZ, MARIA ACEVEDO, SARA CASEN, \\ MYRIAH ROSENGARTEN, MARTHA KOWALCZYK, \\ LINDSAY BLAU PORTNOY \\ Fordham University, New York
}

\title{
DISTINGUISHING FACTS FROM BELIEFS: FUZZY CATEGORIES
}

\begin{abstract}
This paper presents results from five studies that investigate how people perceive the distinction between facts and beliefs. The central question being asked is whether the features that distinguish the categories of facts and beliefs are distinct or overlapping. In each of the five studies, participants are presented with content statements and asked the degree to which they agree with a given statement, the degree to which they think others would agree with it, and whether the statement was a fact or a belief. From these ratings, six possible patterns were derived. The results showed that in many content areas the patterns that describe the statements they categorized as facts and those that they categorized as beliefs had considerable overlap. In addition, participant consensus as to which statements were to be considered facts versus beliefs varied from high to low depending on the specific content being evaluated.
\end{abstract}

Key words: concepts, categorization, naive conceptions

The initial motivation to conduct this research came about a number of years ago when the first author was watching the presidential debates. During these debates, phrases like "It's a fact that...," "The fact is...," and "It's my belief..." were often used. The question raised was not whether the candidates were correct in labeling something as a fact or belief but rather how individuals interpreted and used the categories of facts and beliefs.

Throughout our lives we are bombarded with information from all directions - newspapers, television, magazines, textbooks, just to name a few. Often, they are labeled as a fact or a belief. Moreover, throughout our education, we take classes in different subjects and we are required to memorize, learn, and be able

Address for correspondence: Mitchell Rabinowitz, Graduate School of Education, Fordham University, 113 W. 60th Street, New York, NY 10023, USA. E-mail: mrabinowitz@fordham.edu 
to use declarative information or propositions (statements about things) within that subject area productively for thinking and problem solving. The ability to take in and remember information is very important but equally important is the ability to evaluate the 'quality' of that information. Is it accurate, or is it someone's opinion, and should we regard it as accepted knowledge (Rauch, 1993)?

The ability to distinguish fact from opinion (or belief) is seen as an important skill within our educational system. For example, in New York State, this topic is not only included as a curriculum item as early as elementary school, it is also incorporated within a variety of subject matters (NYSED, 2010). The ability to accurately evaluate information is particularly important given the emphasis of our educational system on teaching students to be thinkers and not just memorizing information presented to them (Dewey \& Bento, 2009; Nickerson, Perkins, \& Smith, 1985).

There is a long history and debate as to how to characterize concepts like fact, beliefs, and knowledge within philosophy. Philosophers have attempted to define the necessary and sufficient conditions that would allow a person to assert that they had knowledge. For example, Plato discussed knowledge as having a justified true belief (JTB). A JTB was defined as a something that is true, a person believes to be true and has justification for asserting that it is true. All the conditions are necessary in order to assert that there was a JTB. Gettier (1963) suggested situations where these two features were not sufficient for attributing knowledge and consequently subsequent discussions have centered around which other features, such as luck or causation, are necessary to attribute knowledge (Starmans \& Friedman, 2012). It is interesting to note that even if additional features are needed within philosophy to define a JTB, recent research has suggested that people often only use the original set of features to define knowledge (Starmans \& Friedman, 2012). Another example from the philosophy of science is the discussion of what the features of a scientific fact are (Kuhn, 1962). A scientific fact is seen as something that has been empirically validated, has been replicated many times by various people in varying contexts and has not been disconfirmed as of yet. While philosophical debates about the nature of knowledge have obviously been more involved than presented here, the general orientation has been to determine the set of features that define the concept. Knowledge is seen as a classical concept.

Within the field of psychology a number of researchers have investigated whether people can distinguish facts from other types of knowledge. For example, Marshe, Meade, and Roediger (2003) investigated whether people could distinguish fact from fiction (see also Marshe, Balotta, \& Roediger, 2005). Goodwin \& Darley (2011), addressing moral beliefs, contrast facts with subjective preferences. Then also, there is the contrast between "matters of fact and matters of opinion" (Banerjee, Yuill, Larson, Easton, Robinson, \& Rowley, 2007). Finally, there is the distinction between fact and fantasy (Johnson, Raye, Wang, \& Taylor, 1979). 
Inherent in all of these contrasts is the assumption that there is a set of features that distinguish facts from other types of knowledge. What are facts? For the most part, facts are represented as propositions that are also considered to be true (Cohen \& Nagel, 1934; Dewey \& Bentley, 1975). Of course, what exactly is true is a matter of discussion within the field of epistemology (James, 2007; Russell, 1995).

How specific are the features that define what a fact is and how easy is it to distinguish these features from the features of other related concepts? Are facts and beliefs fuzzy categories or is there a set of necessary and sufficient features (a classical category)? Are they distinct categories or do they overlap? For example, Wierzbicka (1992) suggested that emotions like anger and sadness "embody different - and fully specifiable - conceptual structures" (p. 539). Alternatively, Greene and Paxton (2009) suggested that there is overlap in the features used to understand honest and dishonest behavior.

To be clear, in this research our goal was not to specify the features that define what a fact is. Rather, we were interested in people's naïve epistemology of how they intuitively relate the concepts of facts and beliefs to statements. We were interested in whether the way they applied the terms to information varied by context, whether people made a clear distinction in how they applied the terms and whether people agreed as to which statements were facts and which were beliefs. In reference to category agreement, McCloskey and Glucksberg (1978) showed that for highly typical category members, participants were in agreement as to the category label. However, for less typical members, participants often disagreed on category membership. Would a similar finding be observed for facts and beliefs?

To address these questions we presented participants with general knowledge statements and statements from specific domains (psychology, biology, history, and politics). Given that our goal was not to assess whether statements were actually facts or whether certain sentence structures were more related to facts vs. beliefs, but rather whether people in general would characterize a statement as a fact or belief, we sampled widely in terms of surface structures and chose declarative statements that were found in textbooks and newspapers. For each statement, we then asked the participants three questions about each statement. First, they were asked, on a scale of one to four, how strongly they agreed with the statement (e.g. 1 = strongly disagree, $2=$ disagree, $3=$ agree, or $4=$ strongly agree). Secondly, they were asked, on a five-point scale, the percentage of the general adult population that would agree with the statement (e.g. $1=0 \%, 2=25 \%$, $3=50 \%, 4=75 \%$, and $5=100 \%) .{ }^{1}$ They were then asked if they thought the statement was a fact or a belief.

\footnotetext{
${ }^{1}$ The agreement dimension was chosen because it was assumed on the part of the researchers that facts should be things that people agreed with and beliefs might or might not be in agreement. There are obviously other features not being sampled in these studies that might distinguish facts from beliefs.
} 
Figure 1. Matrix of Ratings and Pattern Assignment

\begin{tabular}{|c|c|c|c|}
\hline \multirow{2}{*}{\multicolumn{2}{|c|}{ Others }} & \multicolumn{2}{|l|}{ You } \\
\hline & & $\begin{array}{l}\text { Strongly } \\
\text { Disagree }\end{array}$ & $\begin{array}{l}\text { Strongly } \\
\text { Agree }\end{array}$ \\
\hline & $0 \%$ & \multirow{2}{*}{$\begin{array}{l}\text { Pattern 1: } \\
\text { I Disagree, Others Disagree }\end{array}$} & \multirow{2}{*}{$\begin{array}{l}\text { Pattern 4: } \\
\text { I Agree, Others Disagree }\end{array}$} \\
\hline & About $25 \%$ & & \\
\hline & About $50 \%$ & $\begin{array}{l}\text { Pattern 2: } \\
\text { I Disagree, Others Vary }\end{array}$ & $\begin{array}{l}\text { Pattern 5: } \\
\text { I Agree, Others Vary }\end{array}$ \\
\hline & About $75 \%$ & \multirow{2}{*}{$\begin{array}{l}\text { Pattern 3: } \\
\text { I Disagree, Others Agree }\end{array}$} & \multirow{2}{*}{$\begin{array}{l}\text { Pattern 6: } \\
\text { I Agree, Others Agree }\end{array}$} \\
\hline & $100 \%$ & & \\
\hline
\end{tabular}

From this data we assess whether people distinguish facts from opinions. If they do, we can then see whether they agree with one another as to which is which. Further, using the truth and agreement dimensions, we can assess whether facts and beliefs share the same attributes.

From the two rating scales (you and others) six patterns of agreement judgments can be derived that could underlie the categorization process. ${ }^{2}$

- Pattern 1: I don't agree and I don't think others will. (Ratings 1 or 2 on "you" and ratings 1 or 2 on "others")

- Pattern 2: I don't agree but others might or might not. (Ratings 1 or 2 on "you" and rating 3 on "others")

- Pattern 3: I don't agree but I think others would agree. (Ratings 1 or 2 on "you" and ratings 4 or 5 on "others")

- Pattern 4: I agree but I don't think others will agree. (Ratings 3 or 4 on "you" and ratings 1 or 2 on "others")

- Pattern 5: I agree but others might or might not. (Ratings 3 or 4 on "you" and rating 3 on "others")

- Pattern 6: I agree and I think others will. (Ratings 3 or 4 on "you" and ratings 4 or 5 on "others")

See Figure 1 for a visual description of these patterns.

Using these patterns, we derived four possible models that might represent the relation between facts and beliefs that we believe are the most reasonable: Model 1: "distinct features" - facts and beliefs are non-overlapping. In this model the hypothesis would be that there is no overlap between the patterns

\footnotetext{
${ }^{2}$ We could have analyzed the data into 20 different patterns (4 You ratings $x 5$ Others ratings) but decided that the patterns would not have much meaning. Rather, we decided to lose some information by grouping patterns so that they allowed some interpretation. The results would not have changed significantly if we analyzed the data into 20 patterns. The data, however, would have been harder to describe.
} 
that define beliefs and the one that defines facts. Facts would be represented exclusively by Pattern 6 and beliefs by Patterns 1 through 5; that is, if a statement was something that you agreed with and you expected others to agree, it would be considered a fact and other statements would be considered beliefs.

Model 2: "belief creep" - some beliefs can have the same characteristics as facts. The hypothesis within this model was that facts are still statements that are assumed to have high agreement, but beliefs can encompass statements that also hold strong agreement values. Facts are still expected to be represented exclusively by Pattern 6. However, within this model, beliefs could be represented by Pattern 1 through 6; a belief could also be something that you agreed with and expected others would agree. A belief could have the same features (in the context of the current studies) as a fact.

Model 3: "facts creep" - some facts may have some uncertainty in terms of agreement and look like some beliefs. The hypothesis within this model was that there could be some acceptance of a debate about the truthfulness of a statement. In this model, facts would be represented by the use of two patterns, Patterns 5 and 6; that is, in addition to Pattern 6 a fact might be something that you would agree with but you might expect others might or might not agree. Beliefs could be represented by a variety of patterns.

Model 4: "feature overlap" - there is considerable overlap between facts and beliefs in terms of the features used to define them. In this model, facts could be represented by a variety of patterns, similar to those representing beliefs. That is, facts and beliefs would be completely overlapping concepts. In this paper, we will present data from five studies. Each study was identical in terms of methodology but varied in terms of the specific content evaluated.

In each study, participants were first presented with a list of 20 general statements to evaluate using the agreement dimension discussed earlier. These 20 general statements were the same across the five different studies. After the 20 general statements, participants were generally presented with a text that presents some content and then were asked to evaluate statements from that content. In some studies, they were then presented with a text of some additional content and then asked to evaluate statements from the second content area. In study 1, the two content areas were psychology-based: the psychology of memory and the psychology of relationships. In study 2, the two content areas were history-based: World War I and Reconstruction. In study 3, the two content areas were biology-based: the circulatory system and evolution. In study 4 , the content area was general political statements and in study 5 the content area was related to a Bill going through the New York State government called 
the Better Bottle Bill (requiring deposits on bottles of water and similar types of drinks). Since the five studies have similar methodology, the analyses for the five studies will be presented together. We will also present one method section, separating the five studies.

\section{Method}

\section{Participants}

Experiment 1 - Psychology. Twelve college students were recruited from an undergraduate psychology course at a private university in New York City. The sample consisted of 3 males, 9 females, ranging from 20 years old to 22 years old, with a mean age of 21.00 .

Experiment 2 - Biology. Thirty-eight college students were recruited from an undergraduate biology course at a university in New York City. Thirty-two participants were included in the analysis for which there was no missing data. The sample consisted of 12 males, 24 females, ranging from 18 years old to 28 years old, with a mean age of 20.29.

Experiment 3 - History. Seventeen graduate students were recruited from a psychology of learning course at a private university in New York City. The sample consisted of 2 males, 15 females, ranging in age from 21 years old to 27 years old, with a mean age of 23.71 .

Experiment 4 - Political statements. Twenty-eight graduate students were recruited from a graduate course at a private university in New York City. The sample consisted of 1 male, 27 females, ranging from 21 years old to 49 years old, with a mean age of 26.37 .

Experiment 5 - Better Bottle Bill. Twenty-six graduate students were recruited from two psychology graduate courses at a private university in New York City. The sample consisted of 1 male, 25 females, ranging in age from 23 years old to 32 years old, with a mean age of 26.21 .

\section{Materials and Procedures}

In all of the experiments, the stimulus materials were presented in a booklet format. The beginning of the booklet included instructions describing the task that participants would be required to perform. The stimulus materials for all five studies are presented in Appendix 1. The first section of the booklet, for the first three experiments, included a list of 20 statements about general world knowledge such as "A hammer is a tool used to pound nails". The attempt on our part was to present 10 statements that we thought were facts and 10 that we thought were beliefs. The statements were presented in a random order. For each statement, the participants were asked to complete the following three tasks:

1. Rate how strongly YOU agree with the statement using a four-point Likert scale of 1 (strongly disagree) to 4 (strongly agree). 
2. Indicate what percentage of the general population (OTHERS) you think would strongly agree with this statement using a five-point scale of $0 \%$ (no one else would agree with the statement), 25\% (a small portion of the general population would agree with the statement), $50 \%$ (about half of the general population would agree with the statement), 75\% (a majority of the general population would agree with the statement), 100\% (everyone else would agree with the statement).

3. Is the statement a fact or a belief?

Following these statements, in the first three experiments participants were presented with two passages from a given domain that were followed by statements from these passages selected by the researchers. After reading the passages, the participants were asked to rate the corresponding statements on the same three questions used in the first section. Participants were asked to rate their familiarity with the passage topics on a four-point scale (Very Unfamiliar, Unfamiliar, Familiar, Very Familiar). Participants were also asked to report their age, their degree program, and their gender. All statements are presented in Appendix 1.

Experiment 1 - Psychology. The two passages within the psychology domain were excerpted from Gazzaniga and Heatherton (2006). The specific topics featured were the psychology of relationships and the psychology of memory. Half of the participants read the memory passage first followed by the rating of the 10 related memory statements on the three criteria presented above. Then the participants were presented with the relationship passage, followed by the 10 corresponding relationship statements. The other half of the participants were presented the topic stimuli in the opposite order (e.g. relationship passage and statements followed by memory passage and statements).

Experiment 2 - Biology. The two passages within the biology domain included the circulatory system and Charles Darwin's theory of evolution from Purves, Sadava, Orians, and Heller (2001). Half of the participants read the circulatory system passage first and rated the corresponding 10 statements using the same questions presented above. The other half of the participants read the Charles Darwin's theory of evolution passage first and then rated the 10 related statements from the passage.

Experiment 3 - History. The two passages within the history domain featured World War I and Reconstruction from Henretta and Dumenil (2006), and Perman and Patterson (1998). Half of the participants read the World War I passage first and the remaining half of the participants read the Reconstruction passage. They then rated the respective corresponding statements from the passage on the three criteria presented above. Ten statements were presented about WWI and 11 statements were presented about the reconstruction.

Experiment 4 - Political Statements. Participants were initially presented with a list of 10 general statements about general world knowledge that they 
Table 1. Average percentage of statements rated as facts and beliefs for the five experiments

\begin{tabular}{lcc}
\hline & Facts & Beliefs \\
\hline Experiment 1 & $44.2 \%$ & $55.8 \%$ \\
Experiment 2 & $47.9 \%$ & $52.1 \%$ \\
Experiment 3 & $46.7 \%$ & $53.3 \%$ \\
Experiment 4 & $48.8 \%$ & $51.2 \%$ \\
Experiment 5 & $47.5 \%$ & $52.5 \%$ \\
\hline
\end{tabular}

rated on the three questions presented above. This was followed by 20 political statements derived from current events.

Experiment 5 - Political Article (Better Bottle Bill). Participants were presented with 20 general statements about general world knowledge and asked to rate them on the same scale as in the previous experiments. They were subsequently presented with an article from The New York Times regarding the Better Bottle Bill. This was followed by 20 statements taken from the article which they then rated.

\section{Procedure}

The booklets were administered on paper to the participants who volunteered to take part in the experiment. Once they read the instructions and completed rating all of the statements, they returned the booklets to one of the researchers. Participants were allowed to refer back to the passages as often as they needed to. The task was generally completed in 20 minutes.

\section{Results}

Distinguishing facts from beliefs

The first goal was to assess whether the participants were willing to make the distinction between facts and beliefs with these materials. First, we calculated the percentage of statements for each set of general statements that a participant categorized as a fact or a belief. The average percent of statements categorized as facts and beliefs is presented in Table 1 . As can be seen, even though we tried to select statements to ensure that $50 \%$ would be considered facts and $50 \%$ would be considered beliefs, participants in all five studies appeared to have a more restrictive view of what was a fact.

For each of the content areas, the average percentage of statements categorized as facts and beliefs was computed (see Table 2). As can be seen, there was variability across domains as to whether the topics were seen to be fact-laden or 
Table 2. Average percentage of statements rated as facts and beliefs for each of the content areas

\begin{tabular}{lcc}
\hline & Facts & Beliefs \\
\hline Psychology Memory & $63.3 \%$ & $36.7 \%$ \\
Psychology Relationships & $23.3 \%$ & $76.7 \%$ \\
History WWI & $75.9 \%$ & $24.1 \%$ \\
History Reconstruction & $60.4 \%$ & $39.6 \%$ \\
Biology Circulatory System & $88.8 \%$ & $11.2 \%$ \\
Biology Evolution & $53.4 \%$ & $46.6 \%$ \\
Political & $12.8 \%$ & $87.2 \%$ \\
Better Bottle Bill & $52.1 \%$ & $47.9 \%$ \\
\hline
\end{tabular}

belief-laden. That is, the information about the circulatory system was seen as being primarily factual (88.8\%) whereas the information about political issues (12.8\%) was seen as being primarily beliefs. It is interesting to note that participants view areas within a domain as very different (e.g. memory statements were judged to be factual, but relationship statements were judged to be primarily beliefs). In all areas, however, participants did make distinctions between facts and beliefs.

\section{Consensus}

The second goal was to assess whether participants agreed with one another as to which statements were beliefs and which were facts. To assess this, a value of 1 was given if the statement was categorized as a fact and a value of 0 was given if it was categorized as a belief. If all participants categorized a statement as a fact, the statement would have an average value of 1 . If all participants categorized a statement as a belief, it would have an average value of 0 . If half of the participants categorized a statement as a fact and the other half categorized it as a belief (no consensus) it would have an average value of 0.5 . For each of the five experiments, the number of statements within given ranges of the consensus scores for the general statements are presented in Figure 2.

To statistically evaluate whether there was consensus or not, the average consensus values for each statement were converted to a scale that ranged from 0 to 0.4 . This was accomplished by giving a value for how far away from agreement $(0$ or 1) a statement was. The number of statements that had an average value either between $0-0.09$ or between $0.9-1$ was multiplied by the value of 0 . The number of statements that had an average value between $0.1-0.19$ or between $0.8-0.89$ was multiplied by the value of 0.1 . The number of statements that had an average value between $0.2-0.29$ or between $0.7-0.79$ was multiplied by the value of 0.2 . The num- 
Figure 2. Number of statements as a function of average consensus value for general statements

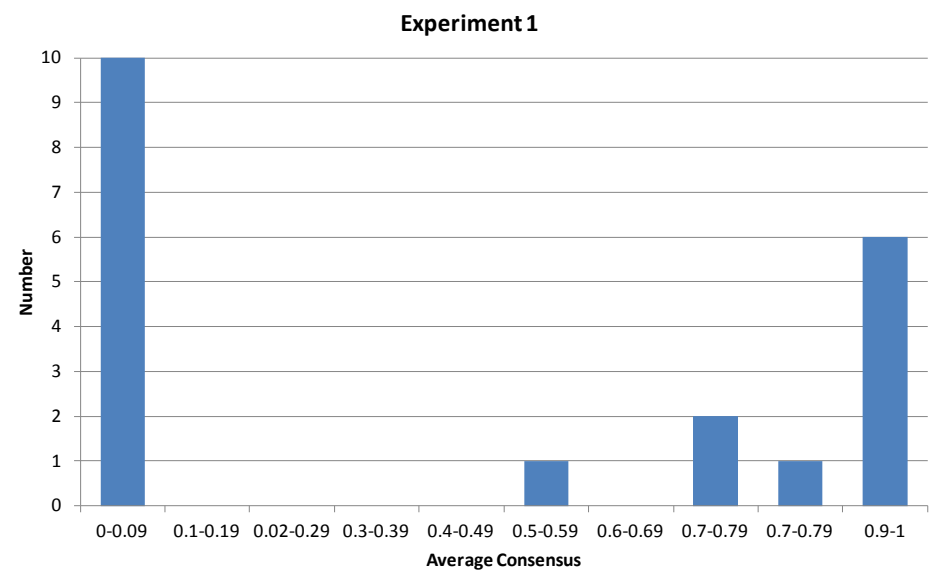

Experiment 2

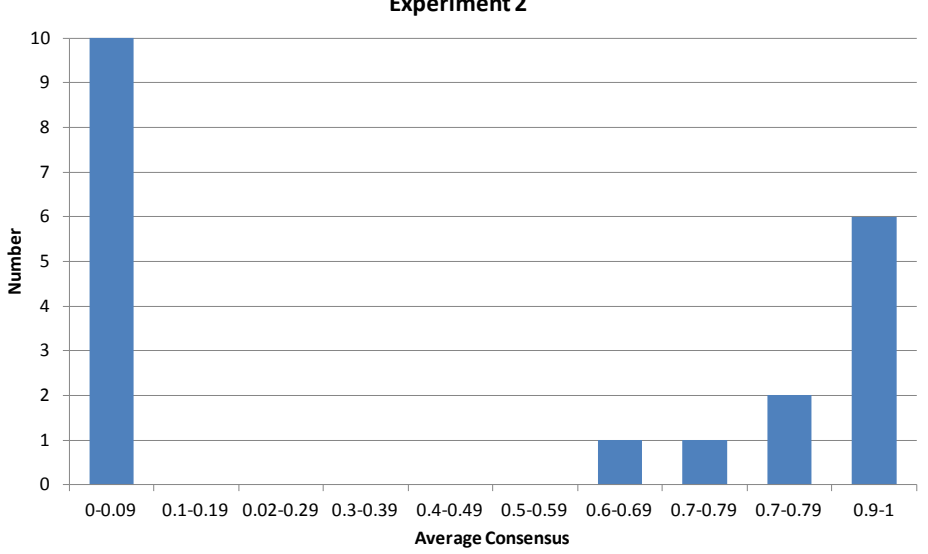

Experiment 3

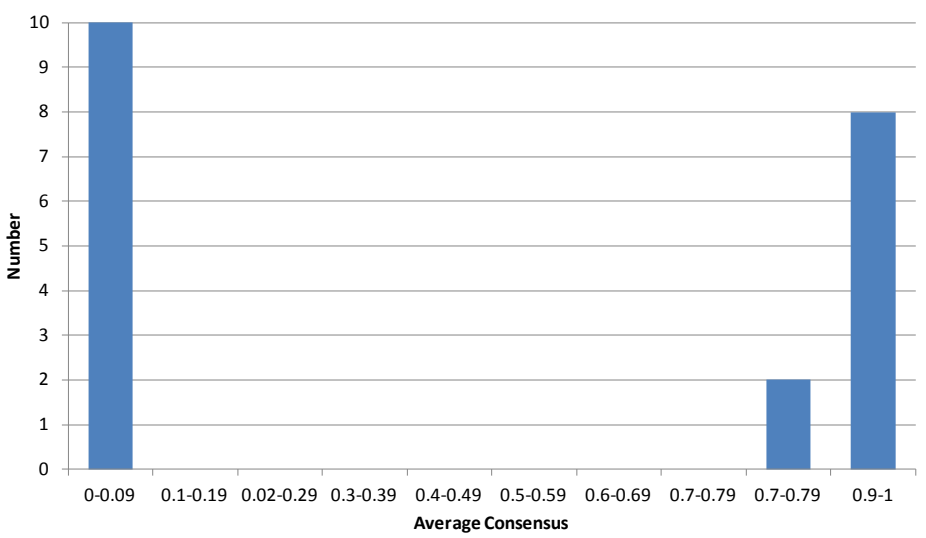



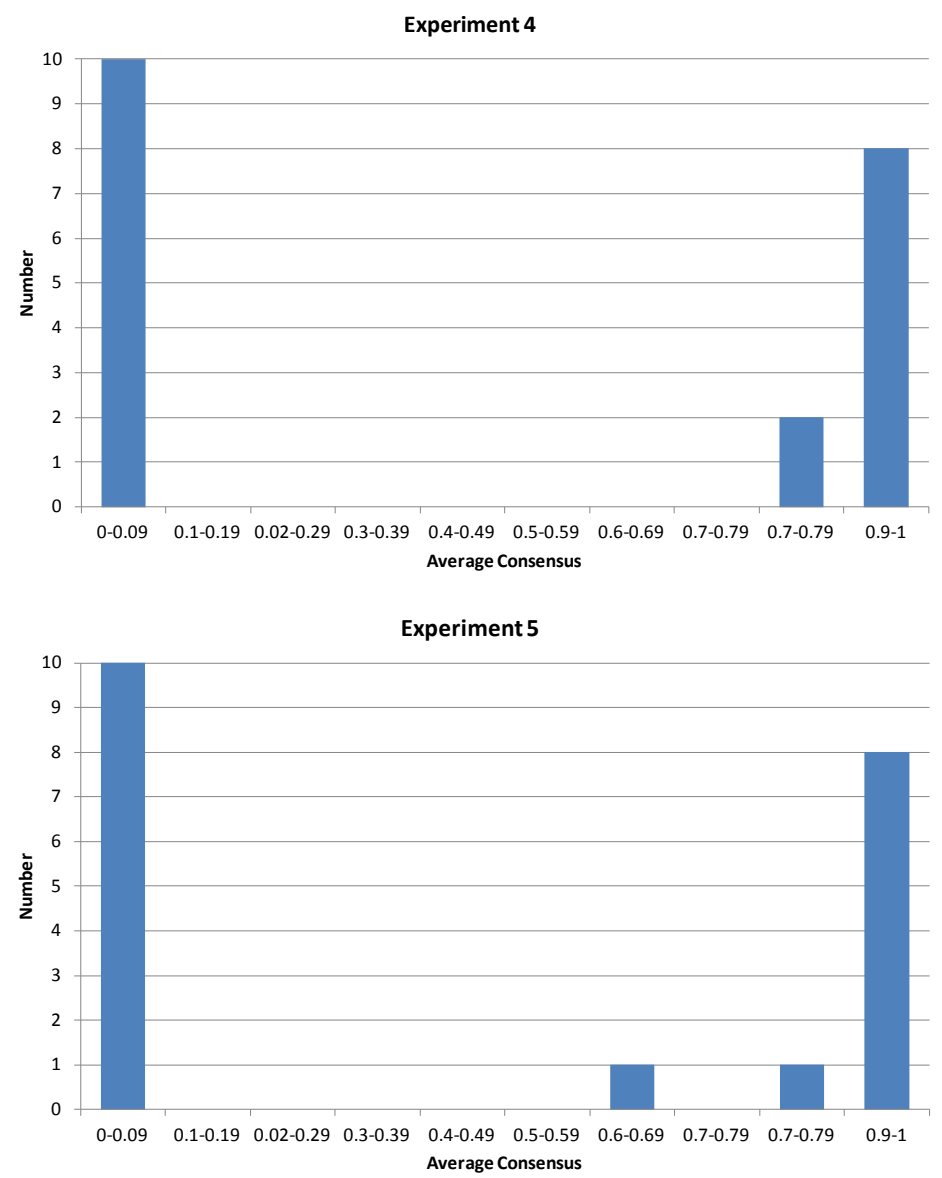

ber of statements that had an average value of either between $0.3-0.39$ or between 0.6-0.69 was multiplied by the value of 0.3 . The number of statements that had an average value of either between $0.4-0.49$ or between $0.5-0.59$ was multiplied by the value of 0.4 . If there were perfect consensus among all participants for all statements (20) the new average consensus value would equal 0.

To assess whether there was consensus or not, the consensus value was compared to the expected value of 0.2 (the expected value if decisions were made by chance or randomly). If the consensus value was significantly less than 0.2 , we assert that there was consensus as to which statements were considered to be facts and which were beliefs. The number of statements within given ranges of the consensus scores for the general statements is presented in Figure 2 for each of the five experiments. The consensus values for the general statements for the five studies were $0.05(t(19)=-6.60, p<0.001), 0.04(t(19)=-9.08, p<0.001), 0.01$ $(t(19)=-27.61, p<0.001), 0.01(t(19)=-27.61, p<0.001)$, and 0.02, $(t(19)=-11.57$, 
Figure 3. Number of statements as a function of average consensus value for content statements
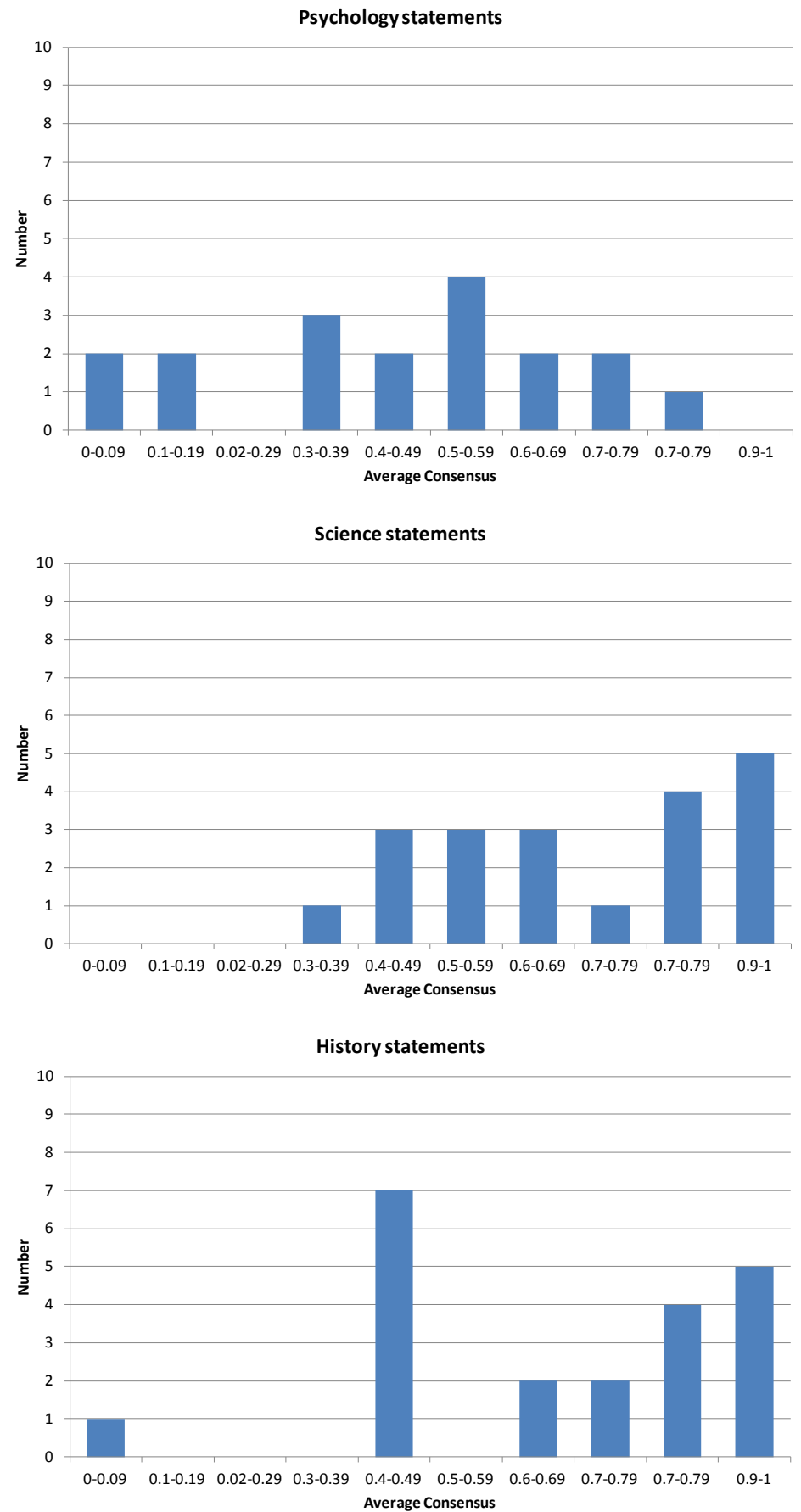

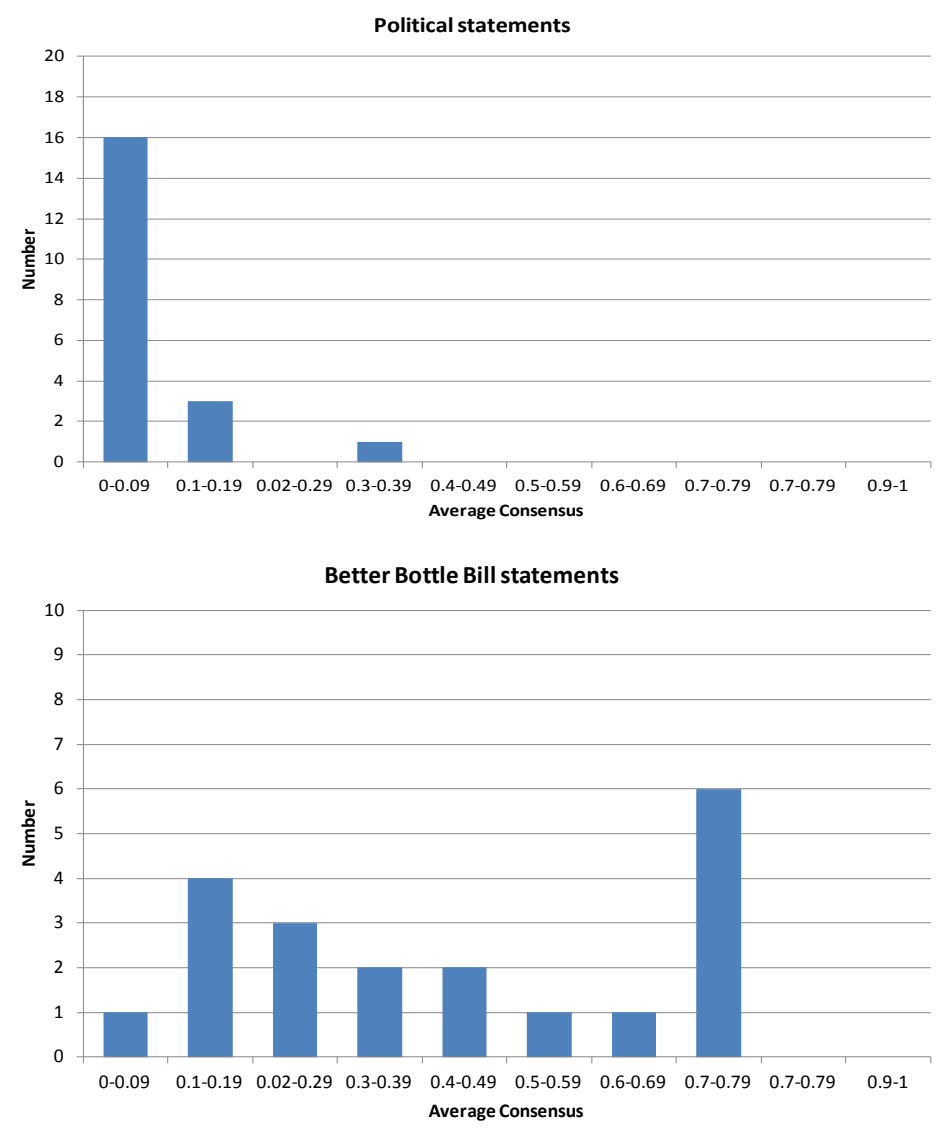

$p<0.001)$ respectively. Thus, for the general statements in all five experiments participants agreed as to which statements were considered to be facts versus beliefs.

The number of statements within given ranges of the consensus scores for the content statements are presented in Figure 3 for each of the five experiments. For the first three studies (Psychology, Biology, and History) the data from the two passages are combined due to the low number of statements for each passage. Note that since there were 10 political statements and 20 statements for the other studies, the vertical axis for the political statements is on a different scale than the other graphs. To assess whether there was consensus or not for these statements, the consensus value was compared to the expected value of 0.2 . The consensus value for the content statements for the five studies were: Psychology $=0.25(t(19)=1.65, p=0.116) ;$ Biology $=0.21(t(19)=0.271, p=0.789)$; History $=0.2,(t(20)=0, p=1.0)$; Politics $=-0.03(t(19)=-10.38, p<0.001)$; and Better Bottle Bill $=0.22(t(19)=0.62, p=0.545)$. As can be seen, for four of the five studies there appears not to be consensus as to which statements should 
Figure 4. Percentage of general statements characterized by each of the six patterns as a function of whether it was categorized as a fact or a belief
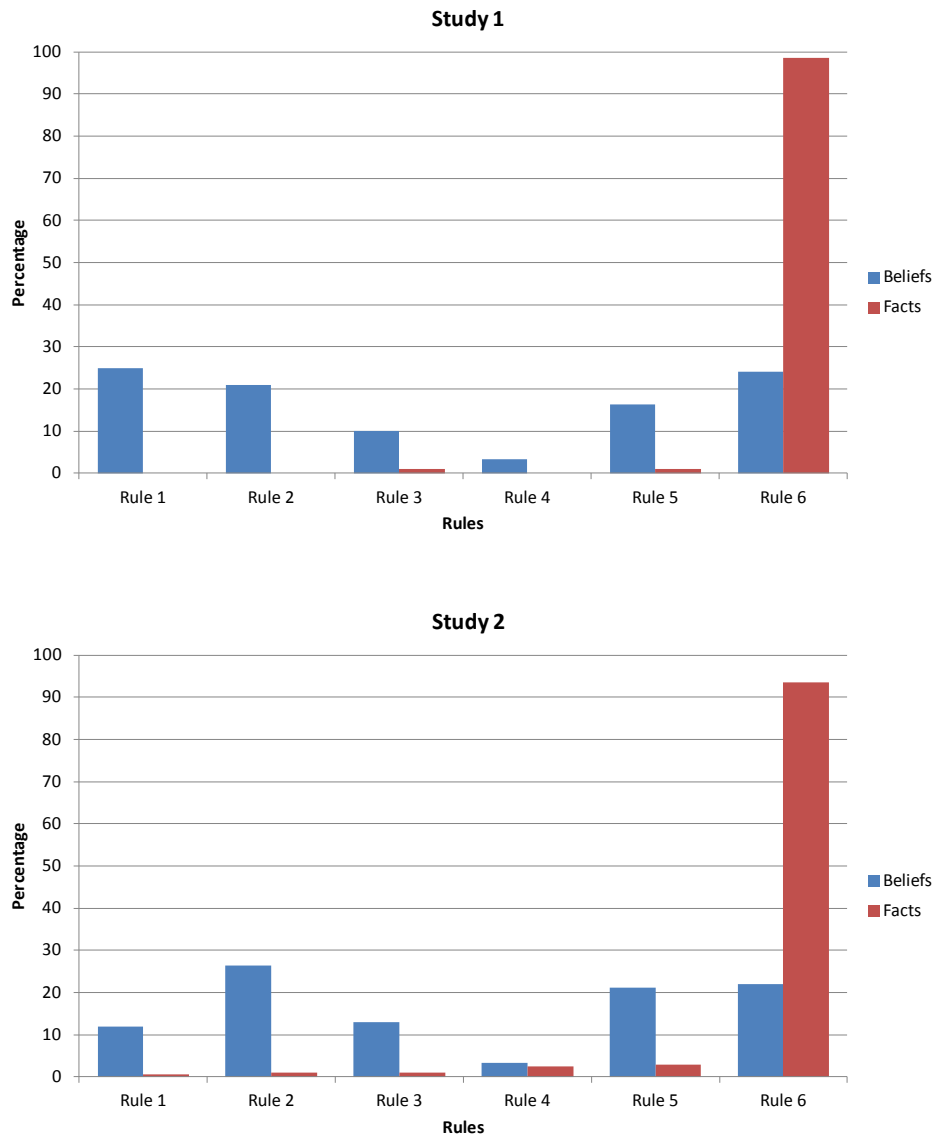

Study 3

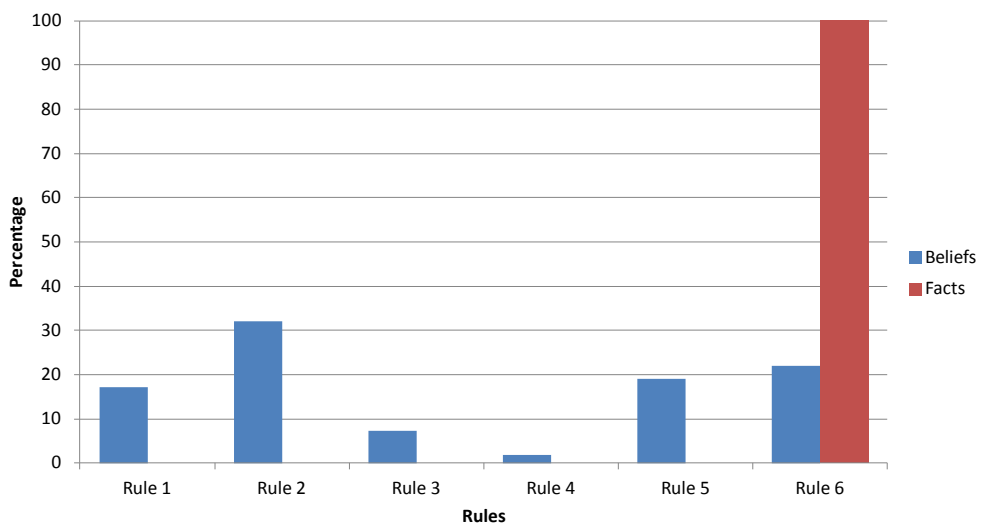



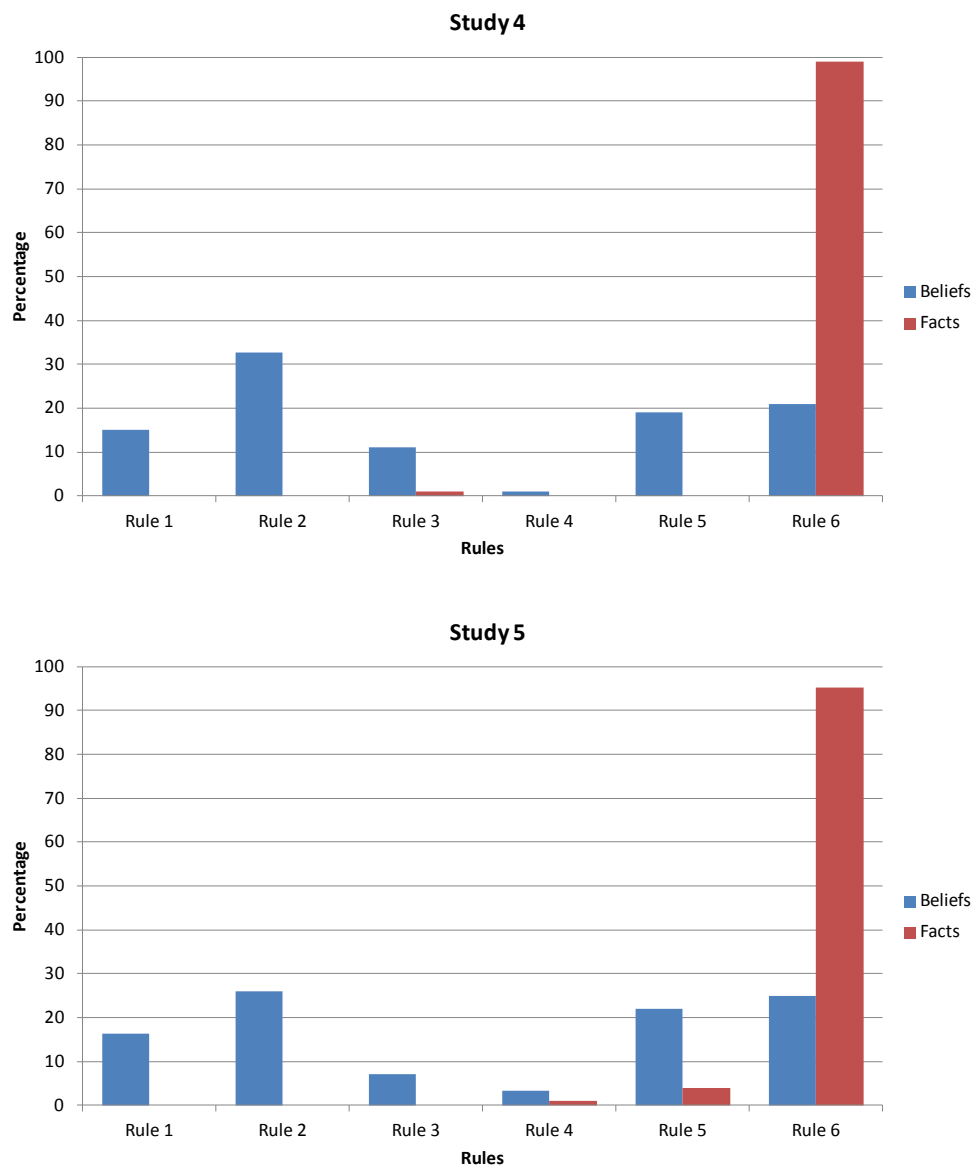

be considered to be facts and which should be considered to be beliefs. Indeed, they are all quite close to chance (0.20). The only content area in which there was consensus was the political domain where practically everyone thought that the statements were beliefs.

\section{Rule patterns}

The third goal was to assess whether participants used the same patterns to describe statements they categorized as facts and beliefs (see Figure 1 described in the introduction). The following analysis does not evaluate whether people were correct in categorizing a specific statement. It basically assesses if the person categorized the statement as a fact or a belief and which pattern was used. Figure 4 shows the pattern of pattern use for the general statements for each of the five studies as a function of whether the participants categorized the statements as facts or beliefs. As can be seen in Figure 4, when statements were categorized 
Figure 5. Percentage of academic content statements characterized by each of the six patterns as a function of whether it was categorized as a fact or a belief
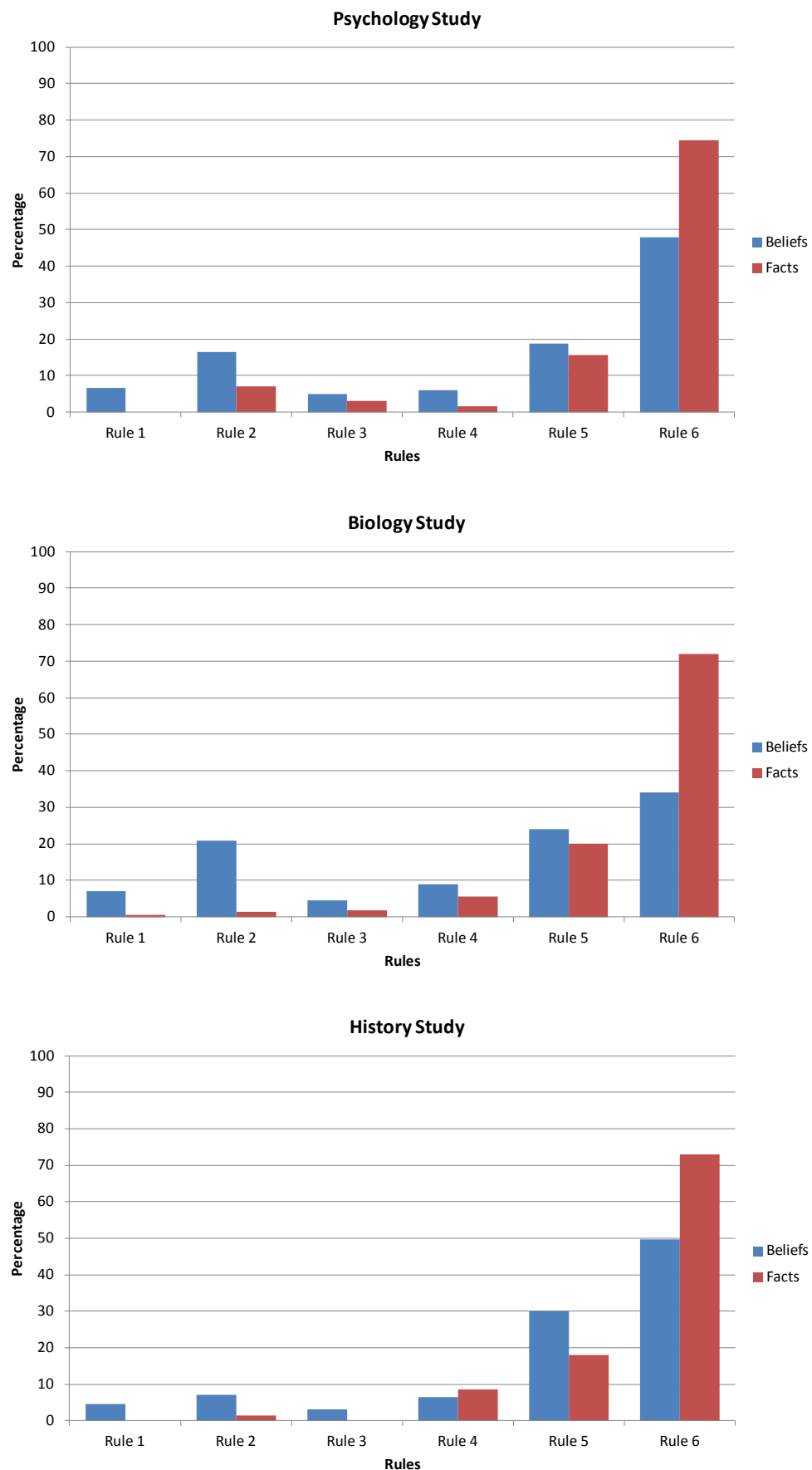
as facts they are primarily represented by Pattern 6: I agree with it and others would agree with it also. For beliefs, all the patterns are used, which is a very different pattern. It appears that participants seem to be hesitant to use Pattern 4 (I agree with it but others would be unlikely to). In contrast, Pattern 1 is often used (I don't agree with it but others would). Further, it is interesting to note that Pattern 6 is used fairly often (I agree with it and others would also). This finding is consistent with our Belief Creep hypothesis where beliefs can be considered to be in agreement by most and yet not be considered to be a fact.

In Figure 5, the patterns of pattern use for facts and beliefs for statements from the academic subject materials (Psychology, Biology, and History respectively) are presented. Once again, in these studies the data from the two passages were combined. In comparison to the pattern use distribution for the general statements, interesting differences are observed. First for facts: while for each three of the academic areas Pattern 6 was still primarily used, a greater number of participants used Pattern 5 (I agree but others may or may not). For the general statements, the percentage of participants who used Pattern 5 for facts was $8 \%$, $16 \%, 0 \%, 0 \%$, and $19 \%$ for Experiments 1 through 5 respectively. For the academic statements, the percentage of participants who used Pattern 5 at least once was $55 \%^{3}, 53 \%$, and $71 \%$, for the Psychology, Biology and History statements respectively. The use of Pattern 5 is supportive of the Fact Creep hypothesis.

For beliefs, the pattern is also a little different than for the general statements. While all the patterns are once again represented, most of the patterns for the academic content areas are in the I agree range. For the general statements, the average summed percentage of Patterns 4, 5, and 6 for the five studies was: $43 \%$, $47 \%, 43 \%, 42 \%$ and $50 \%$ respectively. For academic content, the collective percentage of Patterns 4, 5, and 6 was $72 \%, 68 \%$, and $83 \%$ for the Psychology, Biology, and History statements respectively. Comparisons between the General statements and content statements were significantly different for the Psychology study $(t(11)=3.36, p=0.006)$, the Biology study ${ }^{4}(t(29)=3.29, p=0.003)$, and the History study $(t(16)=6.47, p<0.001)$.

In Figure 6, the patterns of pattern use for facts and beliefs are shown for the political statements and the statements about the Better Bottle Bill. First for facts: similarly to the statements from the content areas, it can be observed that there is a greater use of Pattern 5 for both types of statements. The percentage of people who used Pattern 5 at least once was $40 \%$ for the political statements and $85 \%$ for the Better Bottle Bill statements. What is more interesting, however, is the increased use of Patterns 1, 2, and 3 (I disagree) with this content. In contrast, regarding the general statements, the percentage of participants who used Patterns 1, 2, and 3 to characterize statements they categorized as facts was $8 \%$,

\footnotetext{
${ }^{3}$ One participant was removed from this analysis because s/he did not categorize any statements as facts.

${ }^{4}$ Two participants were removed from this analysis because they did not categorize any statements as beliefs for the academic content.
} 
Figure 6. Percentage of political content statements characterized by each of the six patterns as a function of whether it was categorized as a fact or a belief
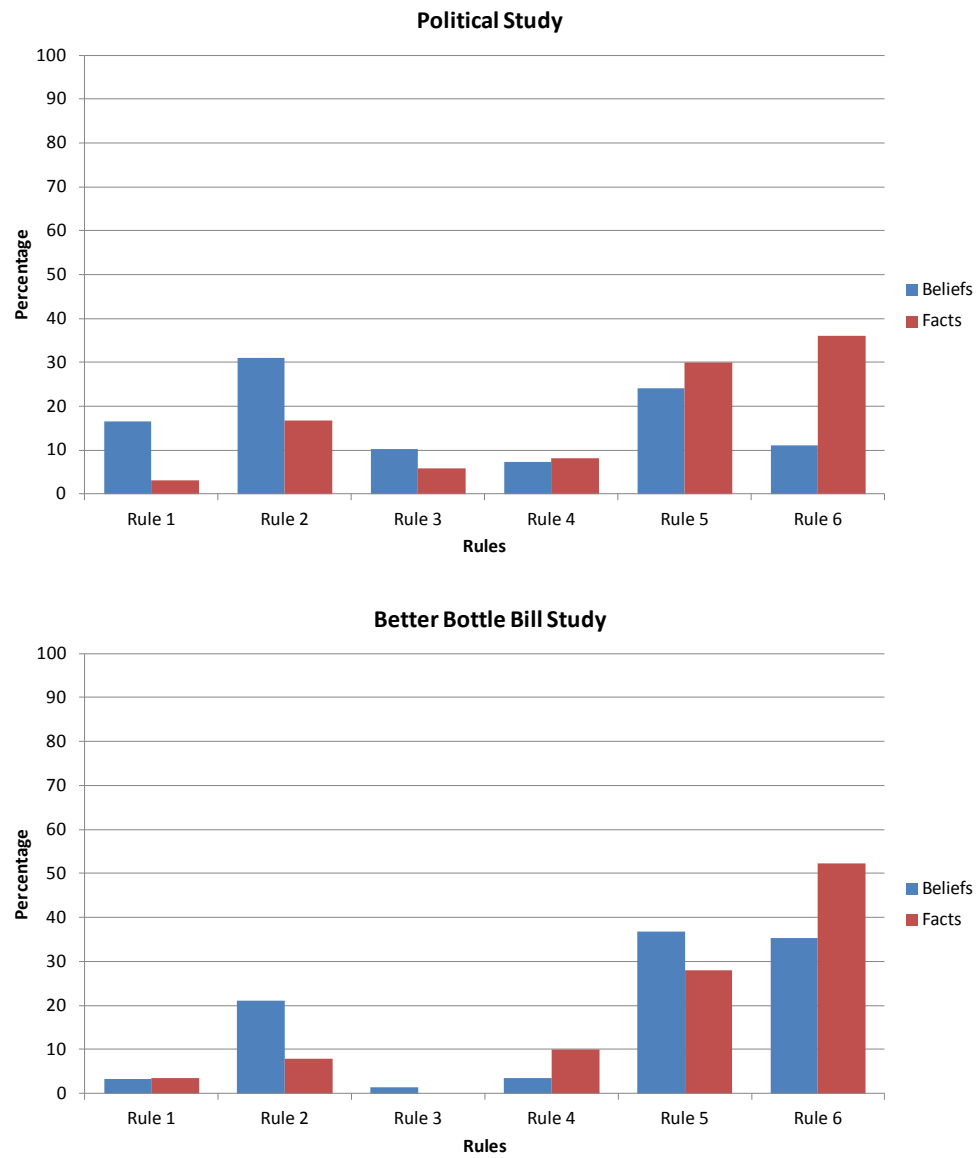

$16 \%, 0 \%, 4 \%$ and $8 \%$ for Experiments 1 through 5 respectively. For the content areas, the percentage of participants who used Patterns 1, 2, and 3 at least once for statements they categorized as facts was $27 \%, 32 \%$, and $12 \%$ for the Psychology, Biology, and History statements respectively. However, for the Political and the Better Bottle Bill statements the percentage of participants who used those patterns at least once to characterize facts was $50 \%^{5}$ and $58 \%$ respectively.

For beliefs, the pattern for the Political statements was different from the academic statements and was more reflective of the responses of the general statements. While all the patterns are once again represented, unlike the academic

\footnotetext{
${ }^{5}$ Sixteen participants were removed from this analysis because they did not categorize any statements as facts for the political statements. Thus, the $\mathrm{N}$ for this analysis was 12 .
} 
statements, most of the patterns for the political areas were not in the I agree range. Once again, for the general statements, the average percentage of Patterns 4,5 , and 6 for the five studies was: $43 \%, 47 \%, 43 \%, 42 \%$ and $50 \%$ respectively. For the political content, the percentage of Patterns 4, 5, and 6 was $42 \%$. However, for the Better Bottle Bill statements it was $75 \%$, similar to those of the academic statements. Comparisons between the General statements and Political statements were not significantly different $(t(28=0.27, p=0.79)$, and for the Better Bottle Bill study it was significant $(t(25)=4.56, p<0.001)$.

\section{Discussion}

The results from these studies suggest that people are quite willing to categorize statements into facts and beliefs but the criteria they use to do so seem to vary as a function of a number of different variables. Domain content is one such variable. That is, one may require less evidence to label something as a fact in certain domains. In the six content domains sampled in Experiments 1, 2, and 3, the percentage of statements categorized as facts varied from $23 \%$ in the case of the psychology of relationships to $89 \%$ for statements about the circulatory system. All statements in all areas were taken from textbooks on the topic. It is interesting to see that history statements were generally regarded as factual even though history is a reconstruction of the past. Further, it is interesting that there was such a large difference in the perception of memory and relationship statements given that both areas used similar statistical methods to evaluate statements.

Also, it is likely that the criteria needed to categorize a statement as a fact vary to some degree from individual to individual. This might explain the general lack of consensus observed across the studies. The only times that consensus was observed were when the statements were specifically designed to sample both facts and beliefs (the general statements) or when most of the statements were categorized as beliefs (the political statements). For the other statements, there was a general lack of consensus as to which were facts and which were beliefs. This finding is very consistent with the results reported by McCloskey and Glucksberg (1978).

These results suggest that across people, the features that people use to distinguish facts from beliefs are not well defined. This perspective is also supported by the pattern use analysis. With the general statements, facts have a clear representation in terms of the predominant use of Pattern 6 (I agree and I expect that others would also). However, the same pattern is often used in reference to beliefs. The distinction between facts and beliefs becomes less clear when the data for the content statements are evaluated. With these statements, there is a greater use of Pattern 5 (I agree, but others may or may not) to describe facts and an increase in Patterns 5 and 6 to describe beliefs. The distinction between facts and beliefs is almost nonexistent when the data for the political statements and 
the statements regarding the Better Bottle Bill are evaluated. For these statements, substantial numbers of participants asserted that they thought a statement was a fact but did not agree with it. Depending on the context, Model 2 - Belief Creep (General Statements), Model 3 - Fact Creep (Academic Domains) and Model 4 Feature Overlap (Political Statements) all seem to have some support.

Our conclusions are clearly limited by the fact that our task primarily assesses the distinction between facts and beliefs in reference to the feature of truth. There are many different features that are relevant to this distinction, such as evaluative versus objective or normative versus non-normative characteristics. Future research should explore whether variability in people's judgments would change by assessing different features.

As previously stated in the introduction, the ability to distinguish facts from beliefs is an important curriculum goal within our educational system. Two implications might be induced from the results of these studies. The first is that our educational system is failing in achieving this goal. The second, and probably more important implication, is that the distinction between facts and beliefs is very fuzzy to people and consequently, the goal of teaching students to be able to distinguish facts from beliefs is a very difficult one to achieve. This might also explain why previous researchers who attempted to assess whether people could easily distinguish facts from other types of knowledge found that people had a difficult job doing so (Banerjee, et al., 2007; Goodwin \& Darley, 2012; Marsch, et al., 2003).

\section{Acknowledgements}

The authors would like to thank Jun Li and Gregory Murphy for very helpful comments on earlier drafts of this manuscript.

\section{References}

Banerjee, R., Yuill, N., Larson, C., Easton, K., Robinson, E., \& Rowley, M. (2007). Children's differentiation between beliefs about matters of fact and matters of opinion. Developmental Psychology, 43, 1084-1096.

Cohen, M.R. \& Nagel, E. (1934). An introduction to logic and scientific method. New York, NY: Harcourt, Brace and Company.

Collins, A.M. \& Quillian, M.R. (1969). Retrieval time from semantic memory. Journal of verbal learning and verbal behavior, 8, 240-247.

Dewey, J. \& Bentley, A.F. (1949). Knowing and the known. Westport, CT: Greenwood Press.

Dewey, J. \& Bento, J. (2009). Activating children's thinking skills (ACTS): The effects of an infusion approach to teaching thinking in primary schools. British Journal of Educational Psychology, 79, 329-351. 
James, W. (2007). The meaning of truth. Radford, VA: Wilder Publications. Johnson, M.K., Raye, C.L., Wang, A.,Y., \& Taylor, T.H. (1979). Fact and fantasy: The roles of accuracy and variability in confusing imaginations with perceptual experiences. Fournal of Experimental Psychology: Human Learning and Memory, 5, 229-240.

Kuhn, T.S. (1962). The structure of scientific revolutions. Chicago: University of Chicago Press.

Gazzaniga, T.F. \& Heatherton, T.F. (2006). Psychological science (2nd ed.). New York: W. W. Norton \& Company.

Gettier, E.L. (1963). Is justified true belief knowledge? Analysis, 23, 121-123.

Goodwin, G.P. \& Darley, J.M. (2012). Why are some moral beliefs perceived to be more objective than others? fournal of Experimental Social Psychology, 48, 250-256.

Greene, J.D. \& Paxton, J.M. (2009). Patterns of neural activity associated with honest and dishonest moral decisions. Proceedings of the National Academy of Sciences USA, 106(30), 12506-12511.

Henretta, J., Brody, D., \& Dumenil, L. (2006). America: A concise history (Vol. 2; 3rd. ed.). Boston: Bedford/St. Martin's.

Marsh, E.J., Balota, D.A., \& Roediger III, H.L. (2005). Learning facts from fiction: Effects of healthy aging and early-stage dementia of the Alzheimer type. Neuropsychology, 19, 115-129.

Marsh, E.J., Meade, M.L., \& Roediger III, H.L. (2003). Learning facts from fiction. fournal of Memory and Language, 49, 519-536.

McCloskey, M.E. \& Glucksberg, S. (1978). Natural categories: Well defined or fuzzy sets. Memory \& Cognition, 6, 462-472.

New York State Education Department (2010). Curriculum Instruction and Instruction Technology. Retrieved 20.06.2010 from http://www.emsc.nysed.gov/ciai/.

Nickerson, R.S., Perkins, D.N., \& Smith, E.E. (1985), The teaching of thinking. Hillsdale, NJ: Lawrence Erlbaum Associates.

Perman, M. \& Paterson, T. (1998). Major problems in the civil war and reconstruction. Boston: Houghton Mifflin.

Purves, W.K., Sadava, D., Orians, G.H., \& Heller, C. (2001). Life, the Science of Biology: The Science of Biology. New York: Macmillan.

Rauch, J. (1993). Kindly inquisitors. University of Chicago Press.

Russell, B. (1940). An inquiry into meaning and truth. New York: W. W. Norton \& Company.

Starmans, C. \& Friedman, O. (2012). The folk conception of knowledge. Cognition, 124, 272-283.

Wierzbicka, A. (1992). Defining emotion concepts, Cognitive Science, 16, 539-581. 


\section{Appendix 1}

\section{General Statements Across Studies}

1) A hammer is used to pound nails. ${ }^{A}$

2) Children are happy and carefree.

3) Dogs are animals.

4) A pen is for writing. ${ }^{\mathrm{A}}$

5) The telephone is the greatest invention of all time.

6) There are three colors in the American flag.

7) There are seven days in a week.

8) Christmas is a holiday primarily for children.

9) Sleeping with the windows open is good for you.

10) Thermometers are used to record temperature.

11) A driver's license is required by law for driving a car.

12) Books may be borrowed from the library.

13) Rich people are happy people.

14) Cats are friendly animals.

15) Rock music has a bad influence on young people.

16) It is okay to lie.

17) The longer you stay in school the smarter you will become.

18) The earth revolves around the sun.

19) Comic strips are funny.

20) The shape of a ball is round ${ }^{A}$

\section{Psychology Statements}

1) Sensory information, such as light, smells, and odors, leaves a trace on the nervous system for a split second and then vanishes.

2) Information that is attended to is passed from sensory stores to short-term memory.

3) Short-term memory or immediate memory can hold information for no longer than about 20 seconds.

4) Meaningful units of information are easier to remember than nonsense units.

5) The more efficiently you can chunk information the more you can remember.

6) Long-term memory is nearly limitless.

7) A filtering system or series of rules limits what is stored into our long-term memory.

8) Information enters permanent storage through rehearsal.

9) Overlearning, in which you keep rehearsing material that you already know pretty well, leads to improved memory, especially over longer periods of time.

10) Studying that is spread out over time, known as distributed practice, is better remembered than material that is studied over a brief period of time, called massed practice, or cramming. 
11) The more often college students came in contact, the more likely they were to become friends.

12) People like things that are familiar more than they like what is strange.

13) People have a general fear of anything novel.

14) People who are similar in attitudes, values, interests, backgrounds, and personalities tend to like each other.

15) People tend to like those who have admirable personality characteristics and who are physically attractive.

16) People who seem overly competent or too perfect make others feel uncomfortable or inadequate.

17) Attractive people are judged to be happier; more intelligent, sociable, and successful, and less deviant.

18) Children as young as six months prefer to look at attractive faces.

19) Mothers treat attractive children differently from unattractive children.

20) Attractive people are considered more popular, socially skilled, and healthier.

\section{Biology Statements}

1) Circulation of molecules is essential for life.

2) In order for life to endure, materials must be transported through the organism.

3) The circulatory system plays a crucial role in the body's immune response.

4) Complex organisms have an open circulatory system.

5) As animals became more complex, their circulatory systems became more intricate.

6) Blood is pumped through the vessels by the heart, then spills out into the blood sinuses and bathes the tissues.

7) As the blood flows over the tissues, nutrients are distributed and wastes collected.

8) The circulatory system found in some invertebrates, like the segmented worms, and in the vertebrates is even more complex than the open system.

9) Whether open or closed, the circulatory system aids the organism in maintaining homeostasis.

10) A closed system in invertebrates carries on an additional function: It transports antibodies to aid in the body's defense against foreign organisms or their products.

11) Species of temperate regions of South America are more similar to those of tropical South America than they are to European species.

12) Animals of the archipelago dispersed from mainland South America and evolved differently on each island.

13) Species are not immutable, they change over time.

14) Evolution is a historical fact that can be demonstrated to have taken place.

15) Populations of all species have the potential for exponential increases in numbers. 
16) Without high death rates, even the most slowly reproducing species would quickly reach enormous population sizes.

17) Although offspring tend to resemble their parents, the offspring of most organisms are not identical to one another or their parents.

18) Slight variations among individuals significantly affect the chance that a given individual will survive and reproduce.

19) Individuals do not evolve, populations do.

20) A major consequence of the evolution of populations is that their members become adapted to the environments in which they live.

\section{History Statements}

1) When World War I erupted in August 1914, most Americans saw no reason to involve themselves in the struggle among Europe's imperialistic powers as no vital U.S. interests were at stake.

2) World War I meant new opportunities, albeit temporary, for white women and for members of ethnic minorities.

3) Between February and December 1916, the French suffered 550,000 casualties and the Germans 450,000.

4) World War I was the first modern war in which extensive harm was done to civilian populations.

5) The machine gun was invented by the American-born Hiram Maxim.

6) Poison gas was first used by the Germans at Ypres in April 1915.

7) At the time of World War I, German Americans made up one of the largest and best-established ethnic groups in the U.S.

8) African American leaders such as A. Philip Randolph viewed World War I as a conflict of the white race only.

9) In December 1915, Henry Ford spent almost half a million dollars to send more than a hundred men and women to Europe on a "peace ship" in an attempt to negotiate an end to World War I.

10) By 1917, U.S. banks had lent the Allies $\$ 2.5$ billion.

11) Economic historians confirm estimates that by the 1870 s, black labor in the fields dropped to one-quarter or one-third of pre-emancipation levels.

12) The withdrawal of black females from wage labor occurred primarily among the wives and daughters of able-bodied men.

13) Black men sought to minimize chances for white male-black female contact by removing their female kin from work environments supervised closely by whites.

14) Freedmen actively participated in postwar Republican politics.

15) Poor whites in the sharecropping system shared the same financial burdens that ensnared black people.

16) Black women differed from their white neighbors because of the greater reliance of their families on the work they did outside the realm of traditional domestic responsibilities. 
17) By the mid-1870s no more than 4 to 8 percent of all freed black families in the South owned their own farms.

18) Freedman's Bureau agents at times doled out less land to families with female (as opposed to male) household heads.

19) Fathers had the last word in deciding which children went to work in the fields, when and for how long.

20) Freedwomen cared not only for members of their nuclear family, but also for dependent relatives and others in need.

21) Southern elites and the northern professional class expressed misgivings about the blacks' attempts to help each other during the 1860 s and 1870 s.

\section{Political Statements}

1) The justice system in our country is fair.

2) Child welfare laws do a good job of protecting children.

3) Newspapers are unbiased sources of information.

4) Stricter gun control legislation will decrease gun violence.

5) Claims of an embryonic stem cell cure for Alzheimer's disease are far-fetched.

6) Medical marijuana is needed to relieve pain which cannot be treated with conventional pain drugs.

7) Prayer in schools violates the basic liberties of school children.

8) Abortion needs to be outlawed in all states no matter what the mother's situation is.

9) American troops need to be withdrawn from Iraq immediately.

10) The government needs to engage in wiretapping for the purpose of national security.

11) Socialized medical care is good for our country.

12) Capital punishment needs to be outlawed in all states.

13) Arranged marriage should be against the law.

14) Politicians are letting terrorists into the country by not securing the borders.

15) Young black men are often denied legal representation.

16) The salaries of sports players are justified.

17) Social Security will begin running a deficit in less than 15 years.

18) Illegal aliens undermine American culture.

19) Immigrants are scapegoated for broader problems.

20) The U.S. needs to boycott the 2008 Olympics in Beijing.

\section{Better Bottle Bill statements}

1) The old bottle bill did not require deposits on non-carbonated beverage containers.

2) The old bottle bill did not mandate that revenues from unclaimed deposits be paid to the State. 
3) New York's 'bottle bill' is one of the State's most successful recycling and anti-litter initiatives.

4) As a consequence of the 'bottle bill', there is less litter and broken glass in our streets, farm fields, playgrounds, parks and beaches.

5) The 'bottle bill' reduced the burden of solid waste disposal that is shouldered by local governments.

6) By requiring beverage companies to provide unclaimed deposits to the State for deposit into the Environmental Protection Fund, the bill will also provide new funding for State and local environmental programs.

7) Bottled water, teas, juices and sports drinks didn't much exist when the initial law was passed in 1982.

8) Millions of bottles and cans from such beverages end up in the trash or littering the environment because consumers lack an incentive to recycle such containers.

9) Expansion of the bottle bill will result in at least $\$ 100$ million for deposit into the Environmental Protection Fund.

10) Expanding the state's Bottle Bill to include non-carbonated beverages would significantly reduce the number of bottles and cans that end up as litter in our neighborhoods, on our beaches, in our parks, and along our waterways and highways.

11) Containers with refundable deposits were found in litter at a substantially lower rate.

12) Passed in 1982, the New York State Returnable Container Act, commonly known as the Bottle Bill, has been highly effective at capturing carbonated beverage containers.

13) In the last 25 years consumer habits have changed, and we must adapt our laws to reflect these changes.

14) Curbside programs are best at capturing recyclables such as soup cans and other products that are typically consumed within the home, but beverage containers pose a different challenge.

15) Since 1982, bottled water, teas, juices and sports drinks sales have grown to $25 \%$ of the market.

16) The deposit system is the most effective way to capture beverage containers because they are typically consumed "on the go" and disposed of away from home.

17) Updating the bottle bill to include non-carbonated beverages will provide an incentive to make our environment cleaner and safer by increasing recycling.

18) The 10 states with deposit systems recovered beverage containers at 2.5 times the rate of states without deposits.

19) Between 1983, when the Bottle Bill went in effect, and 2005, the most recent year for which New York has reported statistics, the Bottle Bill achieved an average redemption rate of $73.6 \%$, with additional containers being captured by curbside programs. 
20) Litter from non-carbonated beverage containers (bottled water, juice, sports drinks, etc.), which are not currently included in the state's nickel deposit system (commonly known as the Bottle Bill), far outnumbered litter from beverage containers currently covered under the state's Bottle Bill (soda, beer, sparkling water, and wine coolers).

${ }^{\mathrm{A}}$ Minor modifications were made to this item in two of the studies. 
